\title{
Conceptual and Procedural Approaches to Mathematics in the Engineering Curriculum: Student Conceptions and Performance
}

\author{
Johann Engelbrecht ${ }^{\mathrm{a}}$, Christer Bergsten and Owe Kagesten \\ University of Pretoria, South Africa ${ }^{a}$, Linköping University, Sweden
}

\begin{abstract}
BACKGROUND
Demands by engineering faculties of mathematics departments have traditionally been for teaching computational skills while also expecting analytic and creative knowledge-based skills. We report on a project between two institutions, one in South Africa and one in Sweden, that investigated whether the emphasis in undergraduate mathematics courses for engineering students would benefit from being more conceptually oriented than the traditional more procedurally oriented way of teaching.
\end{abstract}

\section{Purpose (Hypothesis)}

We focus on how second-year engineering students respond to the conceptual-procedural distinction, comparing performance and confidence between Swedish and South African groups of students in answering conceptual and procedural mathematics problems. We also compare these students' conceptions on the role of conceptual and procedural mathematics problems within and outside their mathematics studies.

\section{DeSIGN/MeTHOD}

An instrument consisting of procedural and conceptual items as well as items on student opinions on the roles of the different types of knowledge in their studies was conducted with groups of second-year engineering students at two universities, one in each country.

\section{RESULTS}

Although differences between the two countries are small, Swedish students see procedural items to be more common in their mathematics studies while the South African students find both conceptual and procedural items common; the latter group see the conceptually oriented items as more common in their studies outside the mathematics courses.

\section{CONCLUSIONS}

Students view mathematics as procedural. Conceptual mathematics is seen as relevant outside mathematics. The use of mathematics in other subjects within engineering education can be experienced differently by students from different institutions, indicating that the same type of education can handle the application of mathematics in different ways in different institutions.

\section{KEYWORDS}

conceptual and procedural thinking, confidence, mathematics

\section{INTRODUCTION}

As is the case in many countries in the world, in both South Africa and Sweden, mathematics teaching at the upper secondary level often has an emphasis on procedural skills 
rather than conceptual understanding. Despite formulations about the importance of reasoning and problem solving in the national curriculum, this tradition is still prevalent in Swedish classrooms (Skolverket, 2003). Even if more conceptually oriented tasks are promoted in national tests, tasks produced by teachers for local assessment are mainly of a routine and procedural nature (Boesen, 2006). As a consequence, students beginning their university studies have often experienced mathematics as a subject with a focus on computational skills and have less training in deeper conceptual thinking. University teachers often complain that first-year students have little understanding of basic concepts of precalculus and even the high achieving students are only better in a procedural way of thinking (Engelbrecht, Harding, \& Potgieter, 2005).

In an environment where most tasks and exams in undergraduate mathematics courses for engineering students are procedural in nature (e.g., the study by Bergqvist, 2007, shows how success on exams in calculus courses in Sweden only requires the memorization of rules and examples) and concepts become formal and conceptually more demanding, it is to be expected that students put their efforts toward mastering the mathematical techniques more than aiming for a deeper understanding. Traditionally, demands from engineering faculties have also been for computational skills. However, there are at the same time high expectations in terms of analytic and creative knowledge-based skills on engineers in the work force, which speaks to a need of conceptual mathematical knowledge. The issue of conceptual versus procedural understanding understanding is also relevant in other fields, such as thermodynamics (Taraban, Definis, Brown, Anderson, \& Sharma, 2007), where research suggests that engineering students strive to develop conceptual knowledge but at low cognitive levels.

This paper reports the results of a project between two institutions, one in South Africa and one in Sweden, that investigated whether the emphasis in undergraduate mathematics courses for engineering students would benefit from being more conceptually oriented than the traditional more procedurally oriented way of teaching. In this project we compare the views of engineering students, lecturers, and practicing engineers of two countries on the role of mathematics in engineering education with a focus on the issue of conceptual and procedural knowledge. Reasons for this comparative design include the fact that differences in culture and organizations may provide insights about each situation, which might otherwise not be apparent. Furthermore, similarities and differences can be discerned which can provide a theoretical basis as well as practical implications for mathematics instruction generally and at each institution in particular.

One of the groups in the research design consists of second-year engineer students. We report on findings from second-year engineering students from both countries. We compare performances between these groups of students as well as their confidence in answering conceptual and procedural mathematics problems. Furthermore we compare these students' conceptions on the role of conceptual and procedural mathematics problems within and outside their mathematics studies as well as about the relevance of these ideas in their engineering studies. The results in this article form only a small part of the entire project in which we address other groups including senior engineering students, practicing engineers, and other colleagues in engineering faculties.

\section{The Conceptual-Procedural Distinction in Mathematics Education}

In this section, the key terms for conceptual and procedural knowledge in mathematics are analyzed with reference to previous research, including work on the effect of employing 
different approaches in teaching with respect to these constructs. Implications for the design of the study are also discussed. In the final two sections we elaborate on framing the empirical investigation within a wider engineering education perspective.

Research on conceptual and procedural knowledge. Proficiency in computation has traditionally been one of the main goals of mathematics education. However, the increasing availability and efficiency of computational tools, such as calculators and computers, seem to imply that at least part of what is commonly included in the notion of procedural knowledge can be achieved without deeper conceptual understanding. It has also been observed that students who, for example, solve an equation correctly, sometimes do not know what to do if the task is to decide if a given number is a solution to the same equation, indicating a poor conceptual understanding of equations. Using the terminology of the anthropological theory of didactics (see Bosch \& Gascon, 2006), mathematical techniques to solve certain types of problems can thus be learned without referring to a discursive level of justification why the techniques work or how the mathematical notions used are to be understood and can be related to other concepts (see Lithner, 2008). Curriculum goals of mathematical education often include both the technical and discursive levels but seldomly show how to design teaching to achieve those learning goals. The terms themselves, procedural and conceptual knowledge, are indeed complex and have been the focus of mathematics education research at least since the 1970s.

The distinction between conceptual (or declarative) and procedural knowledge is commonly used within cognitive psychology (Anderson, 1995) for descriptions of individual knowledge structures. In mathematics education, however, the related terminology is rather confusing where the word knowledge is sometimes changed to understanding, thinking, or fluency, and related terms such as relational and instrumental (Skemp, 1987) refer to different constructs than conceptual and procedural as defined by Hiebert and Lefevre (1986), linked to different rationales for learning. Hiebert and Lefevre describe conceptual knowledge as:

$[\mathrm{K}]$ nowledge that is rich in relationships. It can be thought of as a connected web of knowledge, a network in which the linking relationships are as prominent as the discrete pieces of information. (p. 3-4)

The same authors characterize procedural knowledge as constituted by two components: one consisting of step by step procedures for solving mathematical tasks, and one related to the symbolic representations used in such procedures. They see knowledge not only of concepts and procedures but also of the relations between these two dimensions of mathematics as a key to being competent in mathematics. This is also emphasized by Silver (1986) who adds that conceptual and procedural knowledge seldom are present in "pure" form as distinct entities. Research has shown that this interdependence of conceptual and procedural knowledge is highly complex (Byrnes \& Wasik, 1991; Carpenter, 1986; Peled \& Zaslavski, 2008; Skemp, 1978). According to Silver (1986) conceptual knowledge is neither necessary nor sufficient for procedural knowledge, and procedural knowledge may underpin conceptual knowledge (Artigue, 2007). While the study by Rittle-Johnson and Alibali (1999) suggested that conceptual knowledge may influence procedural knowledge more than the reverse, Baker and Czarnocha (2002) found that conceptual thinking is independent of an individual's ability to use procedural knowledge. 
In mathematics, the complexity described may partly be due to a connection between conceptual and procedural knowledge, on one hand, and the relation between form and content in mathematics, on the other. Bergsten (1990) describes the dynamic of mathematical work by superimposing mathematical content and representation (form) with structure and operation in a theoretically and empirically based model of what he calls mathematical operativity:

The model in Figure 1 is based on the assumption that while one performs mathematical operations on and within mathematical structures, conceptual knowledge may be placed in the lower part of the diagram with procedural knowledge in its upper part. By the vertical dynamics in the model, conceptual and procedural knowledge are strongly linked in mathematical work. Both of these levels draw on the form (such as mathematical symbols) and content of mathematical entities, and the relationships between these two aspects. Depending on the individual student's knowledge about and the connections between the four different dimensions of the diagram, the strength of the mathematical operativity of the student will vary.

With a focus on symbol use in mathematics, Tall et al. (2001) employ the notion of procept (Gray \& Tall, 1994) to analyze the conceptual-procedural gap. From the potential interpretation of many mathematical symbols as pointing to either a process or a concept, a procept is:

[A] cognitive construct, in which the symbol can act as a pivot, switching from a focus on process to compute or manipulate, to a concept that may be thought about as a manipulable entity. (Tall et al., 2001, p. 86)

A procept can thus be seen as a kind of mental bridge between the conceptual and the procedural during mathematical work. In their conception, knowledge development in mathematics is characterized as a progression from the "procedural," where the learner is limited to a specific sequence of steps via more general processes producing "the same effect," to "the proceptual," opening up for flexible thinking.

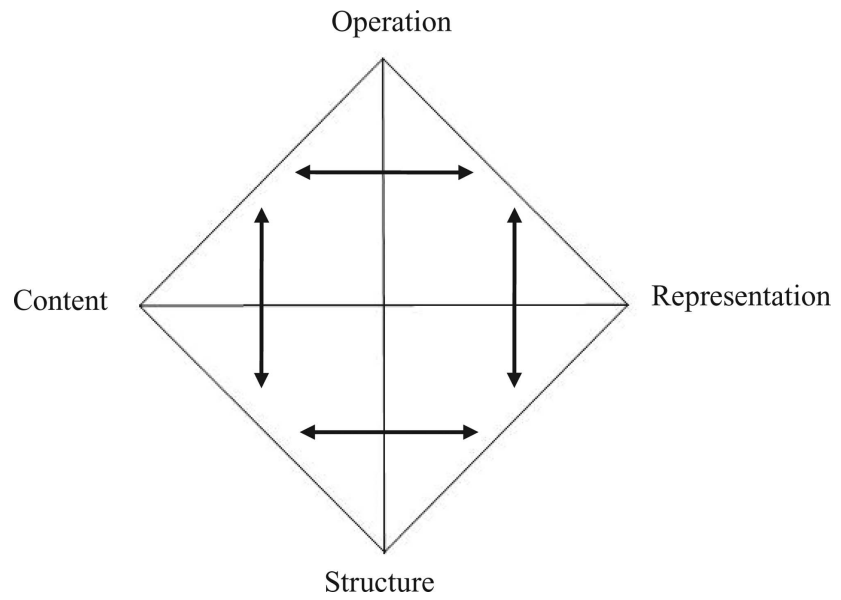

FIGURE 1. Dynamic relationships in mathematical work (from Bergsten, 1990, p. 177). 
Star (2005) points to the problematic issue that definitions of conceptual knowledge commonly state that it is knowledge rich in connections, as in the definition by Hiebert and Lefevre (1986), and argues that both conceptual and procedural knowledge may be deep or superficial. Instead, knowledge development can be described as a dynamic learning process in which disconnected procedural knowledge and weak conceptual knowledge develop by supporting each other, thus growing in parallel (Baroody, Feil, \& Johnson, 2007). This resonates with the conception of different levels of mathematical operativity (Bergsten, 1990) and with the reification process model by Sfard (1991), where progression of knowledge is described in terms of a dynamic process between operational and structural thinking.

There are also studies that point to the need to include other dimensions to model the complex relationship between conceptual and procedural knowledge in an educational setting. The study by Simpson and Zakaria (2004) found a strong correlation between success on conceptual tasks and the use of "linking words" (such as then or because), indicating that "the conceptual students are thinking about the problems in quite different ways from the procedural" (p. 207). Bergsten (2006) used a qualitative interview to study the role of algebra when undergraduate students worked on tasks about limits of functions in a calculus course. The lectures in the course were using the traditional format of introducing theory before applying it to problem solving. In the interviews, students with a strong procedural approach and a high reliance on algebraic manipulations referred to an external authority to confirm their result, while students with a more conceptual approach, using diagrams and numerical reasoning, were more confident with their own internal authority, though often struggling to also base their results algebraically.

Teaching for conceptual or procedural knowledge. The previous discussion raises the issue of whether to teach concepts or procedures first, or in an integrated manner. According to one view, with arguments based on the meanings of mathematical ideas, it is necessary to learn procedures first in order to develop conceptual understanding (e.g., $\mathrm{Wu}$, 1999). This view can be found in traditional curricula, "In the traditional curriculum, concept development is viewed as arising from computational proficiency with relevant procedures" (Baker, Czarnocha, \& Prabhu, 2004, p. 1). In line with this view, it is common that calculus courses start from definitions and theorems, sometimes called the DTP-format, (definition-theorem-proof) (Weber, 2004) to quickly move on to algebraic computations in a procedural manner (Aspinwell \&Miller, 1997).

Such views have been criticized with reference to interpretations of research such as those expressed in the NCTM Standards (Brown, Seidelmann, \& Zimmermann, 2002). Teaching for procedural knowledge would mean presenting, for the students, ready-made definitions, notations and procedures without first providing the deeper meanings to the concepts involved. Teaching for conceptual understanding, on the other hand, would start with problems that require an initial reasoning from the students, to make connections to their prior knowledge (Brown et al., 2002). There is a fundamental difference between these modes of teaching, reflected in the structure of textbooks.

According to recent empirical research, there is strong interference prior to subsequent learning of conceptual and procedural knowledge. Pesek and Kirshner (2000) conducted an experimental study of two groups (approximately 50 grade 5 students in each group), where one group was taught instrumental knowledge before relational knowledge (formulas were given and trained, without providing explanations of why they worked), while the 
other group was taught only relational knowledge (together with the "instrumental" group). The results from pre-, post-, and retention tests, along with student interviews, showed that the "relation" group performed better than the "instrumental" group on items involving both conceptual and procedural tasks. Three different aspects of such interference were observed, i.e., cognitive, attitudinal and metacognitive interference (Pesek \& Kirshner, 2000, pp. 526-527).

Chappell and Killpatrick (2003) found a similar result at the undergraduate mathematics level with a group of 305 calculus students. In one learning environment a procedural teaching approach was used and in another conceptual approach. The students using the conceptual approach scored significantly higher on both conceptual and procedural tasks than the "procedural" group. This was also observed in a replicate study involving 303 students. In undergraduate mathematics education, concept-based instruction can develop conceptual understanding without losing out on the procedural skills. These results were confirmed in Chappell (2006), where a qualitative analysis suggested that knowledge acquired within a concept-based learning environment can be better extended to new situations.

However, using a more detailed qualitative analysis and considering other aspects than achievement levels, the complexity of the relationship between the teaching approach and learning can be more deeply analyzed. Sierpinska (2007) performed a small teaching experiment where the same topic (absolute value) was presented in a lecture in two ways to different groups using a conceptually oriented and a procedurally oriented approach in order to test the hypothesis:

If students in the prerequisite courses were lectured not only on rules, formulas and techniques of solving standard questions but also on some of the theoretical underpinnings of these, then they would have more control over the validity of their solutions and would be more interested in the correctness of their solutions. (p. 51)

In interviews with students no clear cut differences could be found between the groups regarding how certain the students were about the validity of their answers without asking the teacher. Sierpinska suggests a variety of possible explanations for the fact that the teaching approach did not matter much: epistemological, cognitive, affective, didactic, and institutional reasons.

\section{Summary and Implications for the Present Study}

The quote by Sierpinska shows that the distinction between conceptual and procedural knowledge in mathematics is highly complex, with regard to both the meaning of these constructs and the relationships between them when teaching and learning mathematics. The fact that traditional teaching in undergraduate mathematics, including its assessment, tends to put the main emphasis on procedural skills, while at the same time the epistemic value of mastered techniques is still poorly understood, is indeed problematic and points to the need of further research.

The importance of knowing the ways in which conceptual and procedural knowledge interact and contribute to the development of expertise and skills in pedagogical practice has also been widely acknowledged in engineering disciplines (Chi, 2005; Litzinger, Van Meter, Wright, \& Kulikowich, 2006; Taraban, et al., 2007).

For the overall purpose of the present study, we developed tasks that engineering students (in the target populations) generally approached in either a conceptually or a 
procedurally oriented way. The descriptions and analyses of conceptual and procedural knowledge (or understanding or thinking) in mathematics commonly employed in the literature (as discussed earlier), must therefore be operationalized into criteria for what characterizes a solution to a task as mainly conceptually or procedurally oriented. This requires an external language of description to allow an unambiguous reading of the empirical instances linked to an interpretation of the theoretical descriptions provided (Bernstein, 2000). Conceptual knowledge is described as primarily concerned with relations between conceptual entities and their meanings. That is, seeing a structure through a network of relations among these entities and their representations. As it is also linked to prior knowledge including extra-mathematical interpretations and the use of conceptual entities, a conceptual approach to solving mathematical tasks needs to include, among other things, translations between verbal, visual (graphical), numerical, and formal/algebraic mathematical expressions (representations); linking relationships; interpretations and applications of concepts (for example by way of diagrams) to mathematical situations. With an emphasis on how to operate on the mathematical representations to carry out a solution to a task, a procedural approach is characterized by (symbolic and numerical) calculations employing (given) rules, algorithms, formulae, and symbols.

\section{Confidence of Response}

We observed in some studies that students' confidence about the results of their own mathematical work may affect their approach to being more conceptual or procedural. In our study, we therefore wanted to include the students' confidence of their answers to the test items. The idea of investigating confidence of response originated in the social sciences where it is used in surveys. A respondent is asked to provide the degree of certainty he or she has in his or her own ability to select and utilize well-established knowledge, concepts, and laws to arrive at an answer (Webb, 1994). In an academic examination environment a student would be asked to indicate his or her confidence of response along with each answer set. Confidence is usually measured on some scale, in our case $1-4$, where 1 implies a total guess and 4 implies complete confidence. Irrespective of whether the answer is correct or not, low confidence indicates a guess which, in turn, implies a lack of knowledge. If the confidence is high, however, and the answer is wrong, it points to a misplaced confidence in the student's knowledge on the subject matter, either misjudging her or his own ability or a sign of the existence of misconceptions. A confidence measure, in conjunction with the correctness or not of a response, can thus be used to distinguish between a lack of knowledge and either over-confidence or the existence of a misconception (Hasan, Bagayoko, \& Kelley, 1999).

\section{Purpose, Focus, and Design of the Research}

As pointed out previously, this paper forms part of a more extensive investigation whose main objective was to investigate the current mathematical needs of engineers. One question related to the conceptual-procedural issue discussed earlier: should we carry on with equipping students with fluent manipulation skills or should the emphasis move towards a more conceptual presentation of the mathematical concepts and ideas to develop deeper understanding of these concepts? In this study we focus on how second-year engineering students respond to the conceptual-procedural distinction. We compare performances between Swedish and South African groups of students as well as their confidence in answering conceptual and procedural mathematics problems. Furthermore, we compare these students' conceptions of the role of conceptual and procedural mathematics problems 
within and outside their mathematics studies as well as about the relevance of these ideas in their engineering studies.

\section{Research Design}

Development of the instrument. Developing an instrument that can be used with undergraduate engineering students to address the questions mentioned proved a time consuming task. We first developed a draft measuring instrument consisting of 32 items. Of these items, 16 were expected to be solved by a mainly conceptual approach by the target group and 16 by a procedural approach. The construction of the items and the decision about which items were to be classified as mainly conceptual or as mainly procedural were initially made by ourselves and colleagues in the mathematics departments of the two universities.

In constructing the items we used the following working definitions of what we classify as a conceptual or a procedural approach to solving a mathematical task:

Conceptual approach: This includes translations between verbal, visual (graphical), numerical, and formal/algebraic mathematical expressions (representations); linking relationships; and interpretations and applications of concepts (for example by way of diagrams) to mathematical situations.

Procedural approach: This includes symbolic and numerical calculations, employing (given) rules, algorithms, formulae, and symbols.

To ensure construct validity, the test was thoroughly and independently scrutinized by other colleagues to get an unbiased view of the levels of procedural or conceptual knowledge needed to complete each item successfully according to working definitions of the constructs provided (Engelbrecht et al., 2005). Since most items involve some procedural as well as conceptual thinking, we asked colleagues to give us their opinions on the portion of procedural and conceptual thinking that would be required for each item. We used the averages of the colleagues' input after a discussion to confirm or dispute disparities in individual opinions. In the agreement with Anderson (1995) and the earlier discussion, we realized that the procedural and conceptual concepts were not absolute; however, we experienced an impressive cohesion of opinions.

We also realized that experts' opinions on the approach to the solution does not necessarily agree with how students solve problems. To reduce this challenge, the initial draft test consisting of 16 pairs of conceptual and procedural items was written by groups of students at both universities. The format of all items was multiple choice. However, to find out how students approach the tasks, all items were also changed into an open-ended format and we studied the solutions of the sample students. At the South African university, the open-ended test items were solved by groups of third semester (19-20 year old) engineering students ranging between 10 and 30 per group, and at the Swedish university by groups of third semester students ranging between 3 and 6 students per group.

This procedure enabled us to perform a qualitative analysis in order to find out whether students agree with our classification in that they approach the items conceptually or procedurally. We used this analysis in our decision on which items to include in the final version of the instrument and we selected items for the instrument in which the solution approach of students and of experts coincided as conceptual or procedural. 
The outcome of this pilot testing showed a good fit between the expected solution strategy and actual student solutions for many of the items. In fact, in many of the items, all of the students that produced a solution followed the same approach as was predicted by the group of experts. However, we also found some solutions from students that were interesting in the sense that items that were designed to be conceptual were "proceduralized" in sometimes unexpected ways (Engelbrecht, Bergsten, \& Kågesten, 2009), pointing to the complexity of the conceptual-procedural distinction as discussed above.

A second component of the instrument development process included larger comparable groups of students at the South African university doing the instrument in multiple choice format to enable us to do a proper item analysis including calculating the discrimination index as well as finding the level of difficulty for each of the 32 items.

The final instrument. The final instrument was then compiled using four pairs of similar questions. In each pair one question was classified as conceptual by experts and confirmed by the nature of the student solutions and the other item as procedural. In this final decision

- We only used items in which students and experts agreed on whether the item is conceptual or procedural.

- We only used items with a good discrimination index.

- We attempted to pair items together with more or less the same level of difficulty.

- We did not use items that were exceptionally difficult or exceptionally easy.

After answering each item the student had to indicate his or her confidence about the answer he or she provided by indicating whether he or she was positive, almost certain, or uncertain about the answer or whether it was a guess. In addition, after each pair of questions, the student had to indicate which of the two questions, the conceptual or the procedural question, in his or her opinion was

- More common in his or her studies in mathematics.

- More common in his or her other subjects excluding the subject mathematics (outside mathematics).

- More relevant to his or her engineering studies in general.

No question was explicitly labeled as "conceptual" or "procedural" and the order of the conceptual and procedural questions in the four pairs also differed. The following example shows a conceptual item (question A) and a procedural item (question B) along with the follow up questions. Question A is classified as conceptual because mathematical concepts and statements (function, slope, rate of change, increasing function) must be interpreted/applied in relation to a diagram representing a mathematical situation (population size as a function of time). In contrast, Question B is classified as a procedural item: only rules for differentiation must be employed on a mathematical formula followed by a numerical calculation for a specific value of a given variable (symbol).

\section{Example}

Question A. The function $P=f(t)$ in the sketch gives the population after $t$ years. The slope of the line is approximately 300 . Choose from statements A - D which of the statements is NOT true or choose $\mathrm{E}$. 


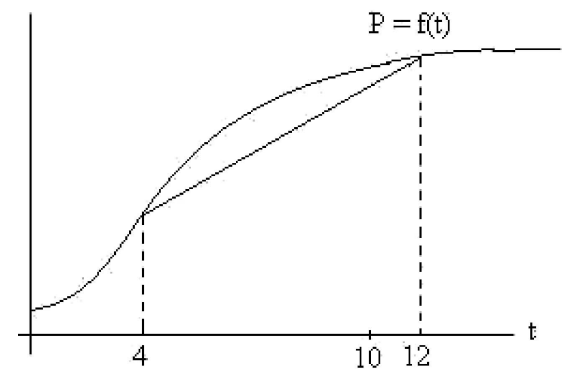
A. The average rate of change of population over the interval $4<t<12$ is 300 people per year.
B. The rate of change of the population at $t=4$ is more than 300 people per year.
C. The rate of change of the population at $t=10$ is more than 300 people per year.
D. The function is increasing.
E. They are all true.

Question B. Find $f^{\prime}(2)$ if $f(x)=3 x \sin \sqrt{x^{2}-3}$
A. $3 \sin 1-12 \cos 1$
B. $-3 \sin 1+12 \cos 1$
C. $3 \sin 1+6 \cos 1$
D. $3 \sin 1+12 \cos 1$
E. None of these

Each of these questions was immediately followed by a question about the student's confidence with the answer:

Indicate how certain you are about your answer:
A. Positive
B. Almost certain
C. Uncertain
D. Total guess

After each pair of questions, three additional questions were asked:

Regarding the types of questions represented by questions $\mathrm{A}$ and $\mathrm{B}$ :

1. Which one of the two questions is more common in your studies within your mathematics courses?

2. Which one of the questions is more common in your studies outside your mathematics courses?

3. Which one of the two questions is more relevant for your studies as engineer?
A. Question A
B. Question B
C. Both
D. Uncertain

The four pairs of questions that were used in the final instrument were on four different mathematical topics, the first pair (as in the example) of differentiation of a single variable function, the second pair on applications (interpretation) of the derivative, and the third pair on differential equations and the last pair on integration.

\section{Target Groups}

All students used in the research are second-year students who have completed initial courses in calculus, differential equations, and linear algebra. 
The two universities are both comprehensive universities and considered to be among the top universities in their respective countries. Both universities have strong engineering faculties and have been training engineers for many years.

In Sweden, students enter the university after completing nine years of compulsory and three years of upper secondary school. The engineering degree program is a five year program. The students at this university can choose between 14 directions, including mechanical, electrical, computer, industrial economy, technical design, and communication systems engineering. In the first two years, the emphasis is mainly on mathematics (30-45\% of course volume) and theoretical subjects such as physics, information technology, and mechanics of materials. The focus gradually moves to more practical, problem-based projects and students finish their degrees with a thesis at a private company or within a research team. The mathematical part of the curriculum consists of courses in single variable calculus (including differential equations, numerical, and power series) and linear algebra in the first year, while in the second year they do courses in multivariable calculus, linear analysis (transforms and Fourier series) and vector analysis. In some of the programs, the students in year 2 through year 4 do courses in optimization, numerical methods, and complex analysis.

Engineering faculties at South African universities follow very much the same structure and the South African university in the study can be considered as representative. Students at the South African university enter university after having attended primary and secondary school for 12 years. These students choose between chemical, civil, mechanical, electrical, computer, aeronautical, industrial, or metallurgic engineering. The engineering program can be completed in four years but the majority of students will study for five years. The program is structured similar to the Swedish program. The first two years are very similar for all the different fields with mathematics as the main component but also some physics, computer science, and chemistry. From the third year the program becomes more specialized and practical. The mathematics part of their curriculum consists of courses in single variable calculus and linear algebra in the first year, while in the second year they do a course in multivariable calculus, a course in differential equations, a course in numerical methods (mostly solving systems of non-linear equations and differential equations) and a course in introductory real analysis (number series, power series and Fourier series) with applications to differential equations.

The instrument was completed by five groups of students.

SW1: A group of 97 third semester mechanical engineering students from the one campus of the Swedish university.

SW2: A group of 60 third semester electrical engineering students from the same campus of the Swedish university.

SW3: A group of 72 third semester mixed engineering students from the other campus of the Swedish university.

SA1: A group of 118 third semester mixed engineering students from the South African university. This was done at the end of their third semester.

SA2: A different group of 240 fourth semester mixed engineering students from the South African university. This was done in the beginning of their fourth semester.

In Sweden we targeted all students in each of the specific programs described. Announced in advance by e-mail, students were asked to volunteer to complete the test immediately after a lecture which was included in the compulsory part of the program. A 


\section{TABLE 1}

Performance and Pearson Correlation Coefficients Between Individual Test Items and Total Marks for the Test

\begin{tabular}{lcccccccc}
\hline Item & $1 \mathrm{~A}$ & $1 \mathrm{~B}$ & $2 \mathrm{~A}$ & $2 \mathrm{~B}$ & $3 \mathrm{~A}$ & $3 \mathrm{~B}$ & $4 \mathrm{~A}$ & $4 \mathrm{~B}$ \\
\hline $\begin{array}{l}\text { Conceptual/ } \\
\text { Procedural }\end{array}$ & $\mathrm{C}$ & $\mathrm{P}$ & $\mathrm{P}$ & $\mathrm{C}$ & $\mathrm{P}$ & $\mathrm{C}$ & $\mathrm{C}$ & $\mathrm{P}$ \\
Performance (\%) & 60.1 & 51.4 & 81.1 & 56.6 & 54.9 & 58.4 & 38.0 & 58.4 \\
Correlation & 0.47 & 0.42 & 0.34 & 0.53 & 0.51 & 0.48 & 0.48 & 0.49 \\
\hline
\end{tabular}

short introduction about the procedure for completing the forms was provided by the researcher. Of course, not all students turned up on the specific day for the lecture but the sample covered a major part of the students enrolled in the specific program. In South Africa a similar procedure was followed. The multiple choice responses were processed by an optical reader and the data were processed and analyzed by the researchers.

\section{RESULTS}

The analysis was threefold:

- a general report on the results of the entire group of 587 students;

- a comparison between the five groups mentioned above; and

- a comparison between students of the two countries, 229 from Sweden and 358 from South Africa.

\section{Item Analysis}

Since the purpose of the test was to investigate students' preferences for conceptual or procedural tasks, it was designed to have items of equal and intermediate levels of difficulty (for the target group) across a variety of types of tasks of relevance for their studies, an inner homogeneity of the test was required. The correlations between the results (performance) of the individual 8 items with the total test results are displayed in Table 1, along with the performance level of each item.

The level and even distribution of the total marks and the correlation coefficients indicate that there was a sufficient amount of homogeneity present between the different items in the instrument (all strongly significant). The only item for which the correlation was somewhat lower (but still significant) is Item 2A which can be explained by the high performance on this item.

General information for the entire group. Figure 2 shows the average performance (as a percentage), and Figure 3 shows the average confidence of all 587 students in the group. To measure confidence, students had to indicate if they were "positive" about their answers (giving a score of 4), "almost certain" would give a score of 3 , "uncertain" a score of 2 , and "total guess" a score of 1 . We compared the students' performance and confidence in the conceptual items with the procedural items.

From these graphs it is clear that in this test, students perform better in the procedural items $(t$-test $p<.01)$ and they are also more confident about their answers to the procedural questions $(t$-test $p<.01)$. 


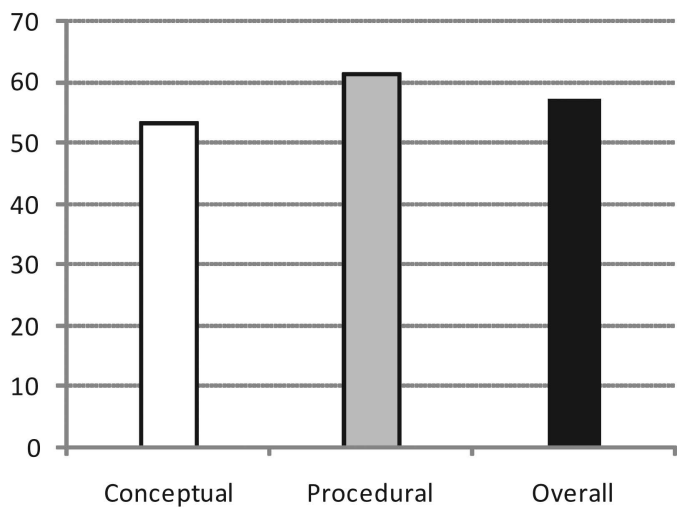

FIGURE 2. Average performance (percentage) of the entire group of students.
4: Positive
3: Almost certain
2: Uncertain
1: Total guess

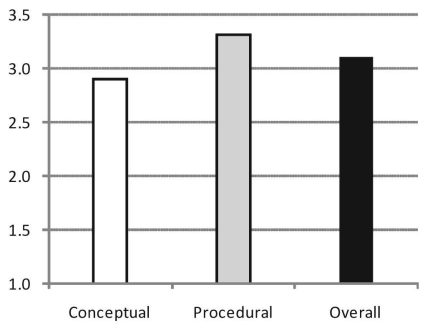

FIGURE 3. Average confidence of the entire group of students.

The Pearson correlation coefficient between performance in the conceptual items and students' confidence in these items is .17 and between procedural performance and confidence it is .31. On this large sample of 587 students both these correlations are significant on a $1 \%$ level of significance.

After each pair of conceptual and procedural questions, the student had to indicate which of the two questions was more common in his or her mathematics curriculum, which was more common in his or her studies outside the mathematics curriculum and which question was more relevant to his or her engineering studies in general. The percentage distribution of all students is given in Figure 4.

From this graph we can conclude that students think that inside mathematics, procedural questions are more common than conceptual questions and that outside mathematics, conceptual questions are more common than procedural questions. Students also see both conceptual and procedural questions as relevant to their studies in engineering in general.

We should add that these students are third or fourth semester students, and thus fairly early in their training as engineers. This means that they have not been exposed much to other engineering courses since the first two years of these programs consist mainly of basic courses such as mathematics and physics. 


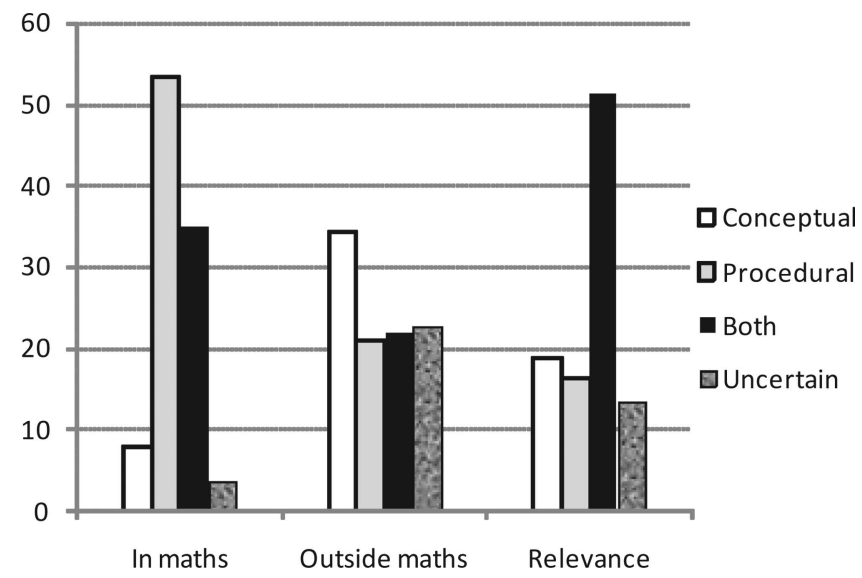

FIGURE 4. Percentage distribution of students' conceptions of items in the mathematics curriculum, outside the mathematics curriculum and relevance in their engineering studies.

Comparison of performance. Figure 5 compares the conceptual and the procedural performance of the five groups (left) and the two countries (right). In this graph the vertical measure is the average mark of students in each group for the conceptual questions, the procedural questions and all the questions.

The only group who performed better in the conceptual items than the procedural questions is the group SW2, the group of electrical engineering students from the Swedish university. All four of the other groups performed better in the procedural questions than in the conceptual. This group (SW2) of Swedish students outperformed all the other groups in both the conceptual and procedural questions and this was expected. In the initial mathematics test for entry to the university they scored significantly higher than the other Swedish group from the same campus and their program included more mathematics studies during the first two years.

The overall performance of the Swedish students (average 59.3\% for the whole test) was somewhat better than that of the South African students (average of 56\%). With a $t$ test $p$-value of .048 this is significant on a $5 \%$ level but not on a $1 \%$ level. The South African students outperformed their Swedish counterparts on the procedural questions with an average of $62 \%$ vs $60 \%$, and the Swedish students performed better in the conceptual questions with $58 \%$ vs $50 \%$. Swedish students performed very similarly in the conceptual and procedural questions - 58\% vs $60 \%(p=.14)$ - whereas for South African students the performances differ significantly $(p<.01)$. In Table 2 the actual numbers for the two countries are given.

Comparison of confidence. In Table 3 we give the average confidence that students reflected in answering conceptual and procedural questions as well as the overall averages for the two countries. Both the Swedish and the South African students showed significantly more confidence in their responses to the procedural questions than to the conceptual questions.

In Figure 6 we compare the confidence of the five groups (left) and students in the two countries (right). All groups expose more confidence in answering procedural questions 

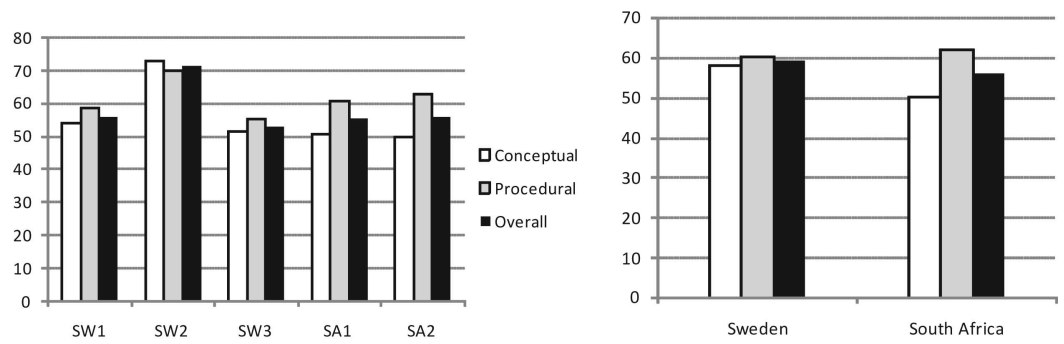

FIGURE 5. Performance (percentage) comparison in conceptual, procedural and all items.

than conceptual questions. These differences are all statistically significant with a $t$-test $p$-value $<.01$ for all cases. The results are very similar for both countries.

Performance and confidence. We also calculated the Pearson correlation coefficients between the students' performance on the conceptual and procedural items, respectively, and the confidence that they have in their responses. This information is reflected in Figure 7.

All correlation coefficients indicate a statistically significant correlation on a $1 \%$ level. However, the correlation is lower for the conceptual items than for the procedural items for both groups, and the correlations for the procedural and, even more so, the conceptual items are higher for the Swedish students than the South African students.

Role in the mathematics curriculum. After each pair of conceptual and procedural questions, the student had to indicate which of the two questions is more common in his or

TABLE 2

Performance Comparison (Percentage) in Conceptual, Procedural and All Items

\begin{tabular}{lcccc}
\hline & Conceptual & Procedural & $t$-test $p$ value & Overall \\
\hline Sweden & 58.2 & 60.5 & 0.29 & 59.3 \\
South Africa & 50.1 & 62.1 & $<0.01$ & 56.0 \\
\hline
\end{tabular}

TABLE 3

Confidence Comparison in Conceptual, Procedural and All Items

\begin{tabular}{lcccc}
\hline & Conceptual & Procedural & $t$-test $p$ value & Overall \\
\hline Sweden & 2.91 & 3.34 & $<.01$ & 3.13 \\
South Africa & 2.90 & 3.30 & $<.01$ & 3.10 \\
\hline
\end{tabular}



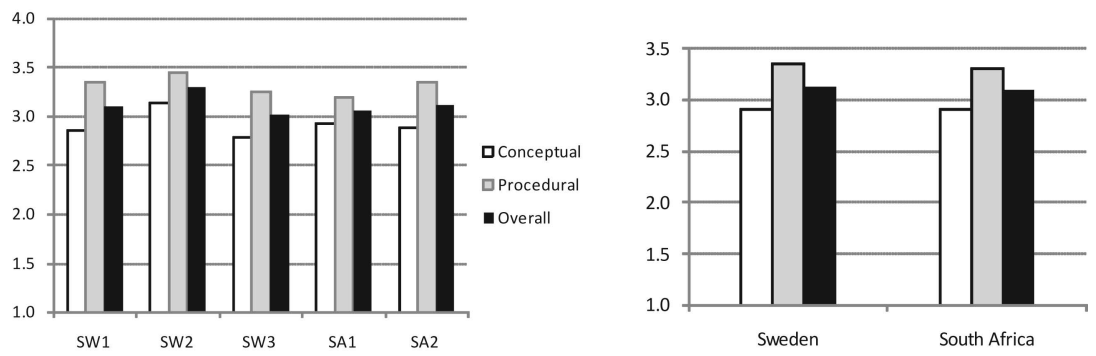

FIGURE 6. Confidence comparison in conceptual, procedural and all items.

her mathematics curriculum. The percentage distribution of the students in the two countries is given in Figure 8 (right). In Figure 8 (left) the five groups are compared.

The data clearly show that all students believe that procedural items are much more common inside mathematics curricula than conceptual items-Swedish students even more so than South African students. The answer category "Both" is as common as the "Procedural" category, indicating a possible difference in the mathematics curriculum as compared to the Swedish institution.

Role outside the mathematics curriculum. After each pair of conceptual and procedural questions the student had to indicate which of the two questions is more common in his or her studies outside his or her mathematics curriculum. The percentage distribution of the students in the two countries is given in Figure 9 (right). In Figure 9 (left) the five groups are compared.

It seems as if South African students to a greater extent see conceptual items as common in their engineering studies outside mathematics. Two of the three Swedish groups still consider procedural questions to be more common in their studies outside mathematics.

For all groups, the numbers of students that are uncertain about this question are higher than for the other questions. This high number of uncertain students on this item makes it somewhat difficult to compare the numbers of students that committed themselves to a definite answer.

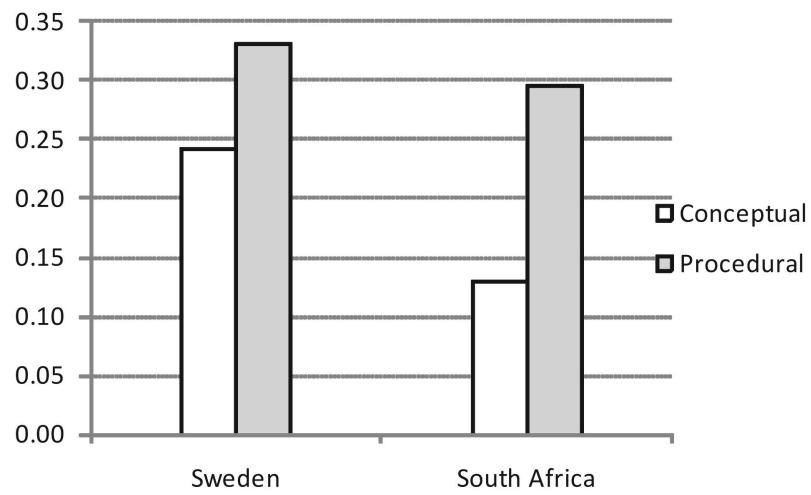

FIGURE 7. Correlation between performance and confidence. 

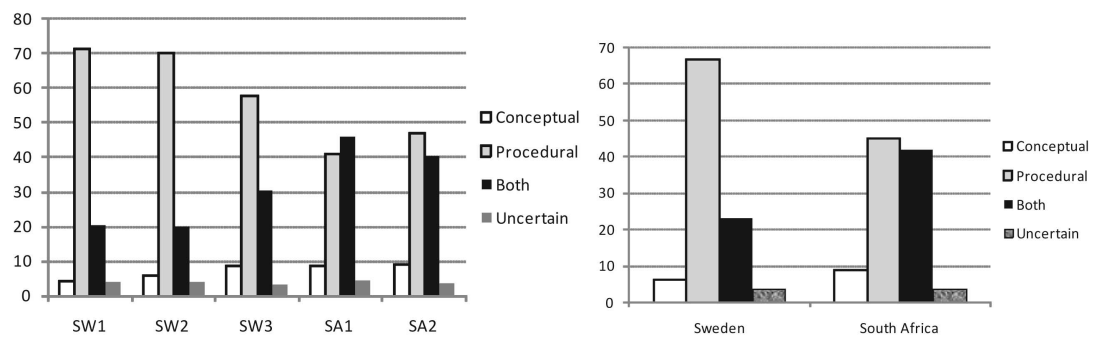

FIGURE 8. Percentage distribution of students' conceptions of items in the mathematics curriculum.

Relevance of items to engineering studies. After each pair of conceptual and procedural questions the student had to indicate which of the two questions is more relevant to his or her engineering studies in general. The percentage distribution of the students in the two countries is given in Figure 10 (right). In Figure 10 (left) the five groups are compared.

For all groups of students, the majority of the students consider both the conceptual and procedural questions as relevant to their general engineering studies. Approximately one third of the students did not respond with the categories "Both" or "Uncertain." Again, the Swedish students seemed to think procedural questions are more relevant and the South African students considered conceptual questions as more relevant to their engineering studies in general.

\section{Discussion AND CONCLUSIONS}

It has been proposed that design is a defining feature of the discipline of engineering and that mathematics as it is normally conceived and taught in engineering education does not support the development of competences critical for design (Winkelman, 2009). In Alpers (2010, p. 2) two major goals for the mathematical component in engineering education are identified: first, the students need to "understand, set up and use the mathematical concepts, models and procedures that are used in the application subjects," and second, "provide students with a sound mathematical basis for their future professional life." Several authors have pointed to the key role of mathematical modeling in engineering education
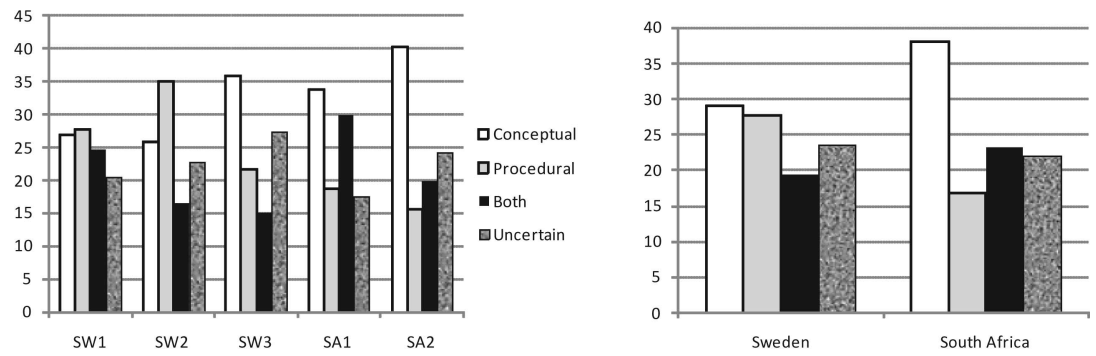

FIGURE 9. Percentage distribution of students' conceptions of items outside the mathematics curriculum. 

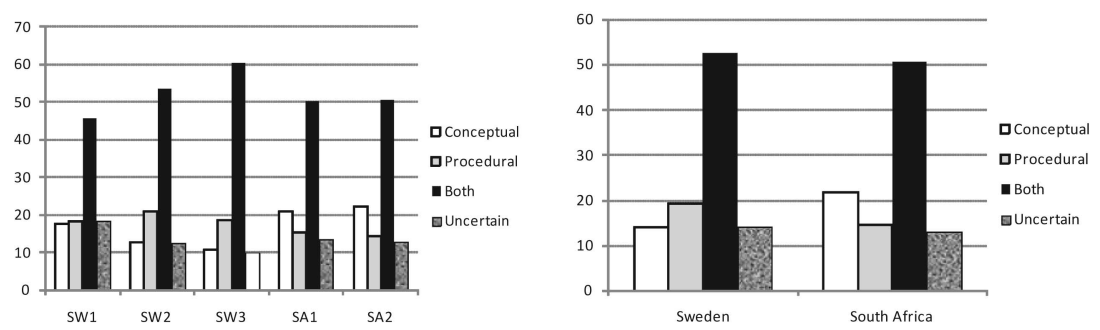

FIGURE 10. Percentage distribution of students' conceptions of items' relevance to engineering studies.

as it is an important tool for engineers and central to engineering practice (Cardella, 2010; Gainsburg, 2006). Consequently, model-eliciting activities in engineering education have been studied (e.g., Moore, Diefes-Dux, \& Imbrie, 2006). In relation to the second goal, Alpers (2010) adds that the mathematical education of engineers should not be restricted to mathematical modeling but also develop an attitude of "skeptical reverence" (Gainsburg, 2007) of the role of mathematics in the work of an engineer. In contrast, Winkelman (2009) found that in engineering education, mathematics is commonly characterized more in terms of intellectual status, gatekeeper, detachment, lack of creativity, and ease of evaluation than as a direct support for engineering design, to which it serves more formally as a foundation and is studied only as a pre-requisite. Such conceptions may well be aligned to a mathematics curriculum in engineering education that puts the main emphasis on procedural fluency rather than on conceptual understanding.

However, learning conceptual knowledge in engineering and science subjects has been identified as critical for learning engineering (Streveler, Litzinger, Miller, \& Steif, 2008). Streveler et al., referring to Redish and Smith (2008), link this to procedural knowledge when they write that "Just as we view conceptual knowledge as applying meanings (as rich as possible) to words such as force, /.../ [mathematical] modeling requires meaning applied to the symbols" (p. 291). Not only manipulating mathematical symbols but also giving meaning to them is thus seen as a way to move from conceptual knowledge to problem solving ability, "because problems generally involve the manipulation of symbols." These authors seem to argue for a mathematics curriculum in engineering education that integrates the conceptual and procedural aspects of mathematical activity, both of which were emphasized as important for engineering studies in the data presented above.

The literature review pointed to a complex relationship between conceptual and procedural knowledge with regard to how to understand these constructs as well as the implications of considering these analytic categories for the organization and outcomes of teaching. Therefore, to evaluate the interpretation of the data from the study presented here, it is important to keep in mind that it is not supported by a critical analysis of the main features of teaching and examinations of the participating students. Instead, the focus here is on how the students themselves experience the conceptual and procedural aspects of mathematics as operationalized through the instrument developed for the study and how they relate these to their studies to become engineers. By comparing two groups of students from different countries with comparable education programs, the observed commonalities and differences may provide viable information of relevance for 
the objective of the overarching project which is concerned with how to design mathematics studies within engineering education.

Although the Swedish students performed slightly better than the South African students for the entire test (Figure 5), this difference is not significant on a $1 \%$ level, thus suggesting that the two groups of students are not that much different with respect to performance. In fact, two of the Swedish groups' performances were very similar to the two South African groups (Figure 5). These similarities provide a rationale for comparisons of the different groups based on the test results. When interpreting the performance results on our instrument, one should also keep in mind that we used the results of the initial item analysis to attempt to make the level of difficulty of questions in each pair similar.

From the data obtained, it seems as if students from both countries perform better in procedural mathematics questions (as indicated in Figures 2 and 5 and Table 1); however, the main contribution to this difference relates only to item $2 \mathrm{~A}$ in Table 1 and they also have more confidence in their abilities to solve procedural questions than in conceptual questions (Figures 3 and 6). These findings are confirmed by the comparison of performance and confidence levels between the groups of students. Only one group (the electrical engineers from Sweden) performed better in the conceptual questions than in the procedural (Figure 5). Care was taken in the design of the instrument after the first pilot test to pair questions together with the same level of difficulty. The better performance in the procedural questions cannot be attributed to the procedural items being "easier."

In all groups, the majority of students have more confidence in their abilities to solve procedural than conceptual problems (Figure 6). However, it is only to be expected that a higher level of performance is mirrored in a higher level of confidence (Figures 2 and 3).

The majority of students from both countries see also procedural questions as more common in their mathematics curriculum (Figure 8), while conceptual questions are seen as more common outside their mathematics curriculum (Figure 9). A speculative explanation for this result could be that students experience mathematics as being more procedural than conceptual and that they experience the applications of mathematics outside the mathematics curriculum as more conceptually oriented. A simpler explanation is probably that mathematics courses, as taught at both institutions, place more emphasis on procedures than on conceptual ideas. This would need to be further investigated by long term qualitative observations of features of lectures, problem solving sessions, textbooks used, and examinations.

On this test, South African students were more fluent in procedural mathematics than their Swedish counterparts, whereas the Swedish students were more proficient than the South Africans in conceptual mathematics questions (Figure 5). In fact, for South African students there was a statistically significant difference (on $1 \%$ level) between their procedural and conceptual performance, whereas for the Swedish students the difference was not significant. This information seems to indicate that the teaching of undergraduate mathematics could even be more procedural in South Africa than in Sweden. However, such conclusions would again need further qualitative investigations of how teaching and examination tasks look at the two institutions.

Interestingly enough, however, a larger portion of Swedish students considered procedural questions as common inside their mathematics courses (Figure 8) and a larger portion of South African students saw conceptual questions as more common outside their mathematics curriculum (Figure 9). This finding is supported by the fact that although more than half of both groups consider both procedural and conceptual mathematics as relevant to their engineering studies in general, a majority of the remaining Swedish 
students regard procedural mathematics more relevant to their engineering studies while the South African students consider conceptual mathematics as more relevant (Figure 10). This implies that although South African students perform better than their Swedish counterparts in procedural mathematics and are more confident about their procedural mathematics than about their conceptual understanding, they are of the opinion that conceptual mathematics is more important to their training in general. Swedish students, on the other hand, outperform their South African counterparts in conceptual mathematics and also have more confidence in their conceptual understanding than the South Africans. In spite of this, they still believe procedural mathematics is more important to their training as engineers. These differences may reflect different emphases between these institutions on the nature of the basic mathematics courses and on making specific engineering perspectives visible early in the studies.

It is not clear how to compare the results shown in Figures 9 and 10. It is evident that these students found both conceptual and procedural items relevant to engineering studies with a low number of uncertain students, while the picture looks quite different when the students were asked about the presence of the same items for studies outside mathematics; here the response category "Both" was much lower and the number of uncertain students much higher. To become an engineer, both conceptual and procedural knowledge are important, but to study the courses outside mathematics (within their studies to become engineers) the conceptual items are considered more common or the student is uncertain. As the procedural items were seen as more common for the mathematics courses, one interpretation of these data is that mathematics is equally important to becoming an engineer as the courses outside mathematics. Another possible implication is that the mathematics courses as well as the courses outside mathematics should be more oriented towards both concepts and procedures. This would agree with prior research that emphasize the deep interdependence between the two constructs.

We also note that while two of the Swedish groups considered procedural mathematics as more common outside the mathematics curriculum, the third group (from the other campus of the Swedish university) agreed with the two South African groups that conceptual mathematics was more common outside the mathematics curriculum. This outcome may be due to differences in the design of the engineering programs between the one Swedish campus and the other, pointing to possible implicit features of such programs that would benefit from being highlighted by research.

Thus, we observed several commonalities as well as differences between how the engineering students at educational institutions in two different countries experienced and conceptualized procedural and conceptual aspects of mathematics in their mathematics studies, as well as in the other parts of their engineering studies. Across different performance levels of the test, one commonality was that an emphasis on both these aspects was seen as important for their studies to become an engineer. This result is significant as it points to a common need of mathematics in engineering education across institutions. On the other hand, we interpret some of the differences previously discussed as an indication that the design of the same type of education, and emphases made in the different courses concerning the conceptual/procedural aspects of mathematics, do influence students' views of both mathematics and its role in engineering education.

It is important to add that our conclusions are based on the findings from only one university in each of the two countries. The differences in population may potentially be attributes to the university rather than the country. This could be a potential limitation to the validity of the results. 


\section{FinAL REMARKS}

A student's pathway towards becoming an engineer, within a tertiary education program, has been described by Stevens, O'Connor, Garrison, Jocuns, and Amos (2008) in terms of the three related dimensions of disciplinary knowledge, identification (as an engineer), and navigation (admittance, passing courses, etc. through an educational program). The overall interest in this paper is the role of mathematics in engineering education, with a focus on what kind of mathematics is and should be taught in terms of conceptual understanding and procedural fluency. To what extent is mathematics (and what kind of mathematics) experienced by the students as "accountable disciplinary knowledge" (Stevens et al., 2008, pp. 356-357), that is, knowledge when performed is counted as engineering knowledge? Standard examination tasks in the basic mathematics courses, most commonly procedural in character, do not belong to this category, but strongly influence the navigation dimension. How then, can mathematics become a part of a student's identity as an engineer? This may be developed later in subsequent courses outside mathematics. The next part of the project will contain data from more senior students as well as practicing engineers to provide further information on these issues.

The students in this study were at the beginning of their studies and one cannot expect most of them to have a clear conception of what is required from them as practicing engineers. However, still having completed a major part of their mathematics studies as well as some introductory "applied" subjects they should have enough experience to have developed a fairly good picture of the character of the mathematics courses as well as the role of mathematics for other subjects. Therefore, the information collected with the instrument should be of relevance when discussing issues concerning mathematics teaching in engineering education. However, it is necessary to have information also from more senior students as well as engineering educators and practicing engineers to be able to further analyze the implications of these data and discuss the role and appropriate emphases of mathematics education for engineering programs.

Quantitative data of the kind presented here can provide useful information on qualitative issues such as different emphases on procedural or conceptual approaches to mathematics education within engineering programs. Knowledge about how large groups of students experience these constructs from the point of view of their mathematics studies and their engineering studies in general is a necessary background in any attempt to change a curriculum with respect to these constructs. Considering the discussions found in previous research, it may be questionable to try to operationalize these analytical categories into test items that discriminate between them. However, based on the pilot testing and qualitative response analysis of the test items used in this study (Engelbrecht et al., 2009), the results presented here show significant differences in how students experience these constructs within their engineering education.

Commonalities in outcomes between the two countries, such as a higher confidence in their performance on procedural tasks than conceptual tasks and the view that both categories of tasks are relevant for their engineering studies, indicate that efforts need to be made to increase students' confidence in conceptually oriented tasks. For example, observed differences in outcomes were that procedural items were seen to be more common in their mathematics studies by the Swedish students while the South African students find both conceptual and procedural items common, and that the latter group saw the conceptually oriented mathematical items as more common in their studies outside the mathematics courses as well. These data show that the use of mathematics in other subjects 
within engineering education can be experienced differently by students from different institutions indicating that the same type of education can handle the application of mathematics in different ways at different institutions. This opens up alternative ways of organizing a traditionally very stable branch of education.

\section{REFERENCES}

Alpers, B. (2010). Studies on the mathematical expertise of mechanical engineers. Journal of Mathematical Modelling and Application, 1(3), 2-17.

Anderson, J. R. (1995). Cognitive psychology and its implications (4th edition). New York, NY: Freeman.

Artigue, M. (2007). Digital technologies: A window on theoretical issues in mathematics education. In D. Pitta-Pantazi \& G. Philippou (Eds.), European research in mathematis education V. Proceedings of CERME6 (pp. 68-82). Larnaca: University of Cyprus.

Aspinwell, L., \& Miller, D. (1997). Students' positive reliance on writing as a process to learn first semester calculus. Journal of Institutional Psychology, 24(4), 253-261.

Baker, W., \& Czarnocha, B. (2002, July). Written meta- cognition and procedural knowledge. Proceedings of the 2nd International Conference on the Teaching of Mathematics (at the undergraduate level), Hersonissos, Crete.

Baker, W., Czarnocha, B., \& Prabhu V. (2004, October). Procedural and conceptual knowledge in mathematics. Proceedings of the North American Chapter of the International Group for the Psychology of Mathematics Education Annual Conference, Toronto, Ontario, Canada.

Baroody, A. J., Feil, Y., \&Johnson, A. R. (2007). An alternative reconceptualization of procedural and conceptual knowledge. Journal for Research in Mathematics Education, 38(2), 115-131.

Bergqvist, E. (2007). Types of reasoning required in university exams in mathematics in Sweden. Journal of Mathematical Behavior, 26(4), 348-370.

Bergsten, C. (1990). Matematisk operativitet. En analys av relationen mellan form och innebåll $i$ skolmatematik. [Mathematical operativity. An analysis of the form-content relationship in school mathematics] Doctoral thesis. Linköping: Linköping University.

Bergsten, C. (2006, July). Trying to reach the limit. The role of algebra in mathematical reasoning. Proceedings of the 30th Conference of the International Group for the Psychology of Mathematics Education (Vol2, pp. 153-160), Prague, Czech Republic.

Bernstein, B. (2000). Pedagogy, symbolic control, and identity. Theory, research and critique (Revised edition). Oxford, UK: Rowman \& Littlefield.

Boesen, J. (2006). Assessing mathematical creativity: comparing national and teacher-made tests, explaining differences and examining impact. Doctoral thesis. Umeå: Department of Mathematics, Umeå University.

Bosch, M., \& Gascon, J. (2006). 25 years of didactic transposition. ICMI Bulletin, 58, 51-65.

Brown, S., Seidelmann, A., \& Zimmermann, G. (2002). In the trenches: Three teachers' perspectives on moving beyond the math wars. Retrieved from http://mathematicallysane. com/analysis/trenches.asp

Byrnes, J., \& Wasik, B. (1991). The role of conceptual knowledge in mathematical procedural learning. Developmental Psychology, 27(5), 777-786. 
Cardella, M. E. (2010). Mathematical modelling in engineering design projects. In R. Lesh, P. Galbraith, C. Haines, \& A. Hurford (Eds.), Modeling students' mathematical modeling competencies (Proc. ICTMA 13), (pp. 87-98). New York, NY: Springer.

Carpenter, T. (1986). Conceptual knowledge as a foundation for procedural knowledge: Implications from research on the initial learning of arithmetic. In J. Hiebert (Ed.), Conceptual and procedural knowledge: The case of mathematics (pp. 113-132). Hillsdale, NJ: Erlbaum.

Chappell, K. K. (2006). Effects of concept-based instruction on students' conceptual understanding and procedural skills. In F. Hitt, G. Harel, \&A. Selden (Eds.), Research in collegiate mathematics education. CBMS Issues in Mathematical Education (Vol. 13, pp. 27-60). Providence, RI: American Mathematical Society.

Chappell, K. K., \& Killpatrick, K. (2003). Effects of concept-based instruction on students' conceptual understanding and procedural knowledge of calculus. Primus, 13(1), 17-37.

Chi, M. T. H. (2005). Common sense conceptions of emergent processes: Why some misconceptions are robust. Journal of the Learning Sciences, 14(2), 161-199.

Engelbrecht, J., Harding, A., \& Potgieter, M. (2005). Undergraduate students' performance and confidence in procedural and conceptual mathematics. International Journal for Mathematics Education in Science and Technology, 36(7), 701-712.

Engelbrecht, J., Bergsten, C, \& Kågesten, O. (2009). Undergraduate students' preference for procedural to conceptual solutions to mathematical problems. International Journal of Mathematics Education in Science and Technology, 40(7), 927-940.

Gainsburg, J. (2006). The mathematical modeling of structural engineers. Mathematical Thinking and Learning, 8(1), 3-36.

Gainsburg, J. (2007). The mathematical disposition of structural engineers. Journal for Research in Mathematics Education, 38(5), 477-506.

Gray, E. M. \& Tall, D. O. (1994). Duality, ambiguity and flexibility: A proceptual view of simple arithmetic. Journal of Research in Mathematics Education, 26(2), 115-141.

Hasan, S., Bagayoko, D., \& Kelley, E. L. (1999). Misconceptions and the certainty of response index (CRI). Physics Education, 34(5), 294-299.

Hiebert, J., \& Lefevre, P. (1986). Procedural and conceptual knowledge in mathematics: An introductory analysis. In Hiebert, J. (Ed.), Conceptual and procedural knowledge: The case of mathematics (pp. 1-27). Hillsdale, NJ: Erlbaum.

Lithner, J. (2008). A research framework for creative and imitative reasoning. Educational Studies in Mathematics, 67(3), 255-276.

Litzinger, T., P. Van Meter, M. Wright, \& Kulikowich, J. (2006, June). A cognitive study of modeling during problem solving. Proceedings of the American Society for Engineering Education Annual Conference E Exposition, Chicago, IL.

Moore, T., Diefes-Dux, H., \& Imbrie, P. (2006). The quality of solutions to open-ended problem solving activities and its relation to first-year student team effectiveness. Paper presented at the 2006 American Society for Engineering Education Annual Conference, Chicago, IL.

Peled, I., \&Zaslavski, O. (2008). Beyond local conceptual connections: Meta-knowledge about procedures. Learning Mathematics, 28(3), 28-35.

Pesek, D. D., \& Kirshner, D. (2000). Interference of instrumental instruction in subsequent relational learning. Journal for Research in Mathematics Education, 31(5), 524-540. 
Redish, E., \& Smith, K. (2008). Looking beyond content: Skill development for engineers. Journal of Engineering Education, 97(3), 295-307.

Rittle-Johnson, B., \& Alibali, M. W. (1999). Conceptual and procedural knowledge of mathematics: does one lead to another? Journal of Educational Psychology, 91(1), 175-189.

Sfard, A. (1991). On the dual nature of mathematical conceptions: Reflections on processes and objects as different sides of the same coin. Educational Studies in Mathematics, 22(1), 1-36.

Sierpinska, A. (2007, July). I need the teacher to tell me if I am right or wrong. In J-H. Woo, H-C Lew, K-S Park, D-Y Seo, (Eds.), Proceedings of the 31st Conference of the International Group for the Psychology of Mathematics Education, Seoul, South Korea, (Vol. 1, pp. 45-64).

Silver, E. (1986). Using conceptual and procedural knowledge: A focus on relationships. In J. Hiebert (Ed.), Conceptual and procedural knowledge: The case of mathematics (pp. 181-198). Hillsdale, NJ: Erlbaum.

Simpson, A., \& Zakaria, N. (2004). Making the connection: procedural and conceptual students' use of linking words in solving problems. In M. Johnsen Høines \& A-B. Fuglestad (Eds.), Proceedings of the 28th Conference of the International Group for the Psychology of Mathematics Education (Vol. 4, pp. 201-208). Bergen, Norway: Bergen University College.

Skemp., R. (1978). Relational and instrumental understanding. Arithmetic Teacher, 26, 9-15.

Skemp, R. (1987). The psychology of learning mathematics. Hillsdale, NJ: Erlbaum and Associates.

Skolverket (2003). Lusten att lära - med fokus på matematik. Nationella kvalitetsgranskningar 2001-2002. Skolverkets rapport nr 221, Stockholm, Sweden.

Star, J. R. (2005). Reconceptualizing procedural knowledge. Journal for Research in Mathematics Education, 36(5), 404-411.

Stevens, R., O’Connor, K., Garrison, L., Jocuns, A., \& Amos, D. (2008). Becoming an engineer: Toward a three dimensional view of engineering learning. Journal of Engineering Education, 97(3), 355-368.

Streveler, R. A., Litzinger, T. Z. A., Miller, R. L., \& Steif, P. S. (2008). Learning conceptual knowledge in the engineering sciences: Overview and future research directions. Journal of Engineering Education, 97(3), 205-212.

Tall, D., Gray, E., Bin Ali, M., Crowley, L., DeMarois, P., McGowen, M., Pitta, D., Pinto, M., Thomas, M. \& Yusof, Y. (2001). Symbols and the bifurcation between procedural and conceptual thinking. Canadian Journal of Science, Mathematics and Technology Education, 1, 81-104.

Taraban, R., Definis, A., Brown, A., Anderson, E. E., \& Sharma, M. P. (2007). A paradigm for assessing conceptual and procedural knowledge in engineering students. Journal of Engineering Education, 96(4), 335-345.

Webb, J. M. (1994). The effect of feedback timing on learning facts: The role of response confidence. Contemporary Educational Psychology, 19(3), 251-265.

Weber, K. (2004). Traditional instruction in advanced mathematics courses: a case study of one professor's lectures and proofs in an introductory real analysis course. Journal of Mathematical Behavior, 23(2), 115-133.

Winkelman, P. (2009). Perceptions of mathematics in engineering. European Journal of Engineering Education, 34(4), 305-316. 
$\mathrm{Wu}, \mathrm{H}$. (1999). Basic skills versus conceptual understanding: A bogus dichotomy in mathematics education. American Educator, 23(3), 14-19, 50-52.

\section{Authors}

Johann Engelbrecht is deputy dean of the Science Faculty and professor of Mathematics, University of Pretoria, 0002 Pretoria, South Africa; johann.engelbrecht@up.ac.za.

Christer Bergsten is professor of Mathematics Education at Linköping University, 58183 Linköping, Sweden; christer.bergsten@liu.se.

Owe Kågesten is lecturer in Mathematics at Linköping University, 58183 Linköping, Sweden; owe.kagesten@liu.se. 